\title{
Ambivalent texts, the borderline, and the sense of nonsense in Lewis Carroll's "Jabberwocky"
}

\author{
MICHAEL TEMPLETON \\ Princess Nourah bint Abdulrahman University (Saudi Arabia)
}

Received: 13/11/2017. Accepted: 18/08/2018.

\begin{abstract}
Taking Carroll's "Jabberwocky" as emblematic of a text historically enjoyed by both children and adults, this article seeks to place the text in what Kristeva defines as the borderline between language and subjectivity to theorize a realm in which ambivalent texts emerge as such. The fact that children's literature remains largely trapped in the literary-didactic split in which these texts are understood as either learning materials and primers for literacy, or as examples of poetic or historical modernist discourse. This article situates Carroll's text in the theories of language, subjectivity, and clinical discourse toward a more complex reading of a children's poem, one that finds a point of intersection between the adult and the child reader.
\end{abstract}

KEYWORDS: Ambivalent text, The borderline, Children's literature, Nonsense poems.

\section{INTRODUCTION}

Maria Nikolajeka demonstrates that children's literature occupies a middle place in the world of literary studies. Children's literature is either studied exclusively as a didactic tool - a literary form that exists entirely to provide stepping stones toward literacy for young readers - or else children's literature is understood as a projection of the author's imagination, a nostalgic portrait of some feature of the author's own youth. This is commonly referred to as the "literary-didactic split" (Nikolajeka, 2005: xi). Indeed, a cursory search of academic databases turns up few strictly critical studies of Lewis Carroll's Through

\footnotetext{
*Address for correspondence: Michael Templeton, College of Languages, English Literature Department, Princess Nourah bint Abdulrahman University; e-mail: Templetonm1@gmail.com

(C) Servicio de Publicaciones. Universidad de Murcia. All rights reserved. Print ISSN: 1578-7044; Online ISSN: 1989-6131

IJES, vol. 19 (2), 2019, pp. 1-18 doi: $10.6018 /$ ijes.362231
} 
the Looking Glass, for example. Most critical works appear in journals such as The Journal of Education, or else the literary critical analyses are quite old, some dating back as far as the 1980s. Indeed, Vallone (1998: 138) writes of the "intermittent acceptance" of children's literature as a legitimate object of study in literary scholarship. Kutzer (1991: 719) explains that even teaching children's literature at the college level requires a mode of interpretation other than the strictly literary, such as the history of childhood. At the other end of the literarydidactic split is the fundamental question of what constitutes literature. Taking as bookends Monroe Beardsley's definition that literature is a work that contains content that is, to a significant degree, implicit (Beardsley, 1981), and Bourdieu's sociological critique that would locate all claims to "literary-ness" as functions of the circulation of cultural capital (Bourdieu, 1984: 4), we would be left in a no-man's land in which a firm understanding of children's literature would become a meaningless question.

Indeed, a survey of literary scholarship reveals that children's literature remains trapped in this literary-didactic split. Even studies that propose to directly define children's literature as a unified genre fail because there is no agreement as to what constitutes "children's literature". Gubar (2011: 210) makes it abundantly clear that scholars of children's literature cannot surmount questions of the nature of childhood, fundamental assumptions regarding the adult understanding of childhood, and historical problems that make it impossible to assign premodern texts to either child readers or adult readers.1 Gubar proposes that "a productive middle ground exists between the extreme positions adopted by the definers and the antidefiners" of children's literature, one that dispenses with essentialist definitions of children's literature, and an opposing view that denies any real category that can be strictly called children's literature (Gubar, 2011: 210-11). This article offers an examination of Lewis Carroll's "Jabberwocky" as a notable example of a literary text that has historically crossed the line as a text read by both adults and children. These texts reveal a border area in literary analysis in which the line between children's stories that dwell principally in the fantastic, and adult texts that engage in complex semantic games, is itself a serious game. Specifically, the assumption that the meanings contained in children's literature are largely explicit, and that the line that places a work in the domain of the literary is in some measure implicit, is a false assumption. Children's literature may well contain implicit meanings that require external intervention to fully grasp. Nonsense language provides a realm in which we may examine the border region where a text widely regarded as a children's text operates with linguistic mechanisms that far exceed its obvious content. In other words, the use of nonsense language and poetic forms reveals something critical about the use of language in literary texts more generally, and this linguistic game has everything to with the acquisition of language and subjectivity. It is in this region of language 
and linguistic confusion that the implicit aspects of children's literature are revealed. Nonsense poems operate in a realm of language that shares features with both the onset of language acquisition and the forms of nonsense that are symptomatic of insanity, and this blurred region of language adds a dimension to our understanding of children's literature in the larger context of literary scholarship.

The goal of this article is to situate Carroll's Through the Looking Glass within the context of critical cultural studies more than as an example of children's story. Its aim is to circumvent the simple literary-didactic split and locate these texts in the discourse of literary studies more generally. Carroll's nonsense poems are seen as either fitting nicely into the box of quaint stories intended for the amusement of children and reproduced into Disney ideals, or else they evoke Victorian cultural anxieties regarding language as becoming detached from a fixed reference (Williams, 2013). These anxieties over language reveal further problems with Carroll's own logic, and demonstrates a metalanguage that defies conventional logic in which "the dialogue between logic and literature seems to develop between the two poles of conscious and unconscious knowledge" (Marret, 1993: 217). And yet, these types of analyses lead others to place Carroll's nonsense poems in the larger discourse of modernism (Rother, 1974). Finally, Carroll's nonsense poetry can be interpreted as symptomatic of Victorian concerns with childhood psychology (Schatz, 2015: 96). In this last case, the poems themselves stand as symptoms of psychological disturbance. 2 We may also allow for Michael Holquist's assessment of Carroll's poetic system in The Hunting of the Snark, that "it best dramatized the attempt of an author to insure through the structure of his work that the work could be perceived only as what it was, and not some other thing; the attempt to create an immaculate fiction, a fiction that resists the attempts of readers, and especially those readers who write criticism, to turn it into an allegory, a system equitable with already existing systems in the non-fictive world" (Holquist, 1999). This would place "Jabberwocky" in a singular place wherein it is comparable only to itself. However, Holquist links Carroll's poetic wordplay with other modernist authors who produced singular worlds that are valued in ways that are distinctly a part of the literary establishment. In placing Carroll's "Jabberwocky" in relation to Antonin Artaud's attempt to translate the poem, the current paper will demonstrate that the poem reveals a borderline in the unconscious wherein language is not fully regulated. It is on this borderline where the immature reader and the adult reader find a point of common interpretive understanding.

\section{THE LINGUISTIC BORDER AND “JABBERWOCKY"}

Julia Kristeva (1982) theorized the notion that the border between language and the nonlinguistic is preserved in the human psyche. At the border between the fully integrated self and 
the pre-linguistic infant psyche, there emerge forms of expression that do not properly constitute language, but operate within the terrain of language. Nonsense words, empty sounds, and echolalia do not convey meaning in a conventional sense. Nevertheless, these things border on meaning, and become meaningful within a specific context. These are sounds that convey meaning where "something irreducible to language emerges" (Barzilai, 1991: 296). This is a complex psychoanalytic concept, but this theory reveals a preserved psychic space that remains, albeit repressed, and escapes into linguistic formations that clearly resemble conventional language even as it flouts the norms and rules of conventional language.

Barzilai locates one specific case to exemplify Kristeva's theory in relation to literary production: the prelinguistic infantile stage of language acquisition. As the infant is ushered into language and subjectivity, there is a period in which the child experiments with language in forms such as echolalia, glossolalia, and other linguistic but nonsensical utterances. The phases of childhood language acquisition fall into "several recognizable but overlapping phenomenological stages, namely, (a) prelingual, (b) random articulation or babbling, (c) lalation, (d) imitation (echolalia), and (e) articulate utterance (including symbol formation)" (Eveloff, 1971: 1897). We can see nearly all of these at various points in "Jabberwocky." Echolalia is of particular importance, since it demonstrates a phase in which the child begins to match their own utterances with the utterances of adults. We can recognize examples of echolalia in "Jabberwocky" with words that resemble the sounds and actions that animate the poem. For example:

One-two! One-two! And through and through

The vorpal blade went snicker-snack!

He left it dead, and with its head

He went galumphing back.

No matter the translation we later receive from Humpty Dumpty, these lines operate in the manner of echolalia of poetic language found in adult literature such as Beowulf. The play with consonants and vowels resembles the translation of heroic language from the ancient AngloSaxon epic. Compare this line with couplets from Beowulf:

There would be no monsters gnawing and gloating

Over their banquet at the bottom of the sea.

Instead, in the morning, mangled and sleeping

The sleep of the sword, they slopped and floated

Like the ocean's leavings. ${ }^{3}$ 
We see close associations with the alliterative nonsense in "snicker-snack with" "morning, mangled." The word "vorpal" shares phonic associations with the open vowels contained in the lines from this translation of Beowulf, even as this language is tied to the same images of monsters. While Beowulf uses sophisticated poetic language, "Jabberwocky" mimics this language in ways that are strikingly similar to the way children mimic adult language in the form of echolalia.

This infantile use of language would remain a passing phase and even an exception but for Kristeva's assertion that this phase of language acquisition is preserved in the unconscious. This borderline is revealed in forms of madness and schizophrenia in which patients lose touch with the unconscious symbolic structures which underpin semiotic functions. As one approaches this borderline space, in a healthy ego it elicits fear, but in an ego that has become unraveled through mental illness, this borderline space can become explicitly articulated in the form of nonsense and delusional speech. Since this borderline is in fact preserved in all speaking subjects, it defies the clinical and the medical and is manifest in aesthetic forms. In Kristeva's formulation (1982: 7), "borderline subjects and their speech constitute propitious ground for a sublimating discourse ('aesthetic' or 'mystical,' etc.), rather than a scientific or rationalist one." This theory opens the possibility that nonsense poems such as Carroll's and others are in fact marvelous aesthetic achievements rather than merely fantastic children's playthings or nostalgic projections from adult authors.

\section{PRESERVING THE BORDER IN NONSENSE POETRY}

The children's stories and poems that seem to occupy the popular imagination with the most lasting impact are those texts that can transcend the narrow confines of children's literature and find a broader audience by also appealing to adult readers. These texts manage to provide the child reader (or listener) with a captivating tale while they convey depths of meaning that equally captivate a mature reader. Shavit (1991) describes these as ambivalent texts not so much in the sense that they cannot be properly placed, but because they offer more than one voice, which reaches the reader on different levels depending on how the text is read. To say that the ambivalent text simply finds common ground between the adult and the young reader is a vast oversimplification. Ambivalent texts reach two fields of understanding, both of which have specific criteria by which they provide meaningful messages, albeit for entirely different reasons. Though the child reader may well require conventional modes of meaning, these modes are nevertheless rich in cognitive content. The adult reader demands a different mode, which reaches a more complex cognitive space - the text carries some deformation of the obvious conventional 
mode, which allows for greater complexity than is immediately apparent. These deformations can be achieved in several ways:

While one of the models is conventional, more established and thus addresses the child reader, the other, addressing the adult-reader, is less established, more sophisticated, and sometimes based on the deformation of the more established model. The deformation of the latter is accomplished in several ways: parodization of some elements; bringing into the model new elements; changing the motivation for existing elements; changing the functions and hierarchy of elements; changing the segmentation of the text; breaking the rules of time and space, etc. (Shavit, 1991: 78).

The current article suggests that these types of deformations can be broken down further into sub-categories. For example, the use of a conventional poetic form can remain completely intact, even as the content that fills that form defies basic rules of meaning. In the case of nonsense poems like "Jabberwocky," we have an obvious poetic form that is easily recognizable even to an immature reader, but many of the words themselves are complete gibberish. Nevertheless, the meaning of "Jabberwocky" comes through. For the child reader, the appeal may be the nonsense language itself. For the adult reader, the poem presents a puzzle that almost demands to be taken quite seriously even as it retains the childlike love of nonsense. The exact nature of the ambivalence of these texts remains at a level that may not be obviously apparent to either the child or the adult reader. Rather than fitting neatly into one category or another, nonsense poems blur the line between simple amusement and serious literary/cultural issues.

In "Jabberwocky," its word formations, rhyme and meter, and suggestions of verbal structures make it clear to the adult reader that this is a narrative poem. Something akin to Beowulf emerges in the tone and movement of the poem. Carroll himself provided such an explanation in an earlier version of the first stanza that appeared in a private, handwritten magazine. He explained that the poem was "a curious fragment" and a "stanza of Anglo-Saxon poetry" (Carroll, 1931: 328). The nonsense words in the opening stanza are explained, humorously, as archaic usages of known words. Carroll's mock exegesis resembles what we get from Humpty Dumpty in the finished version of Through the Looking-Glass, and for this reason we must read these explanations as part of the fun. And yet the poem makes sense in terms of the joke itself. While ancient Anglo-Saxon alliterations remain in the forms of "gyre and gimble," Carroll's nonsense version relies on modern rhyme over ancient alliteration. By borrowing and manipulating the ancient formal qualities of this type of poem, Carroll lulls us into a tacit faith in the validity of the nonsense as ancient Anglo-Saxon verse: 
'Twas brillig, and the slithy toves

Did gyre and gimble in the wabe:

All mimsy were the borogroves,

And the mome raths outgrabe.

We see the mix of modern rhyme in the alternating lines and the ancient alliteration contained in the lines. Even without consulting either Carroll's or Humpty Dumpty's explanation of the nonsense words, we can recognize the form of an ancient heroic poem. Clearly, Carroll's poem demands at least two responses: either we read the poem as a type of linguistic play, as a child reader would, or we are compelled to decode the poem using other intellectual tools, as adult readers would. Either it is merely playful, or it is a puzzle.

The opening line is a description of conditions. Although we cannot properly know the meanings of "brillig" or "slithy," we can safely conjecture that they are adjectives that describe the conditions of the opening scene. This shows us that even in the absence of linguistic coherence, we can determine some kind of meaning based on the arrangement of terms and the formation of the words. Context, suffixes, word order, metrical arrangements - all allow us to make some sense of the nonsense of the lines. Raymond J. Rundus offers a clear analysis of some parts of some of "Jabberowcky" from the vantage point of a linguist:

Carroll has retained the function words of the English language (determiners, prepositions, expletives, conjunctions, auxiliary verbs) while filling the remaining slots with "nonsense" words whose grammatical function is signaled syntactically and/or by inflection. Thus "gyre" and "gimble" are both clearly parts of a compound predicate because of their position following the common English auxiliary "did" and their being linked by the coordinate "and." Syntactically, "toves" must be a noun because it follows both the determiner "the" and "slithy," which is given adjectival force because of its "-y" suffix, and also because "toves" precedes and clearly governs the compound predicate. (Rundus, 1967: 958-959)

That a strict linguistic analysis reveals such a wealth of information about a poem composed entirely of pure nonsense tells us that there is much more going on in the poem than pure nonsense. It certainly carries tremendous weight as a cultural artifact. In "Jabberwocky," we tap into a wealth of linguistic and syntactical formations, which can be sorted into categories of understanding.

For the child reader, the play of these words resembles the nonsense uttered by young children as they come to learn language. Made-up words that sound like real words, and 
overblown importance in language that they know to be silly, are characteristic of children's word games. The poem operates on the level of childhood make-believe, complete with a makebelieve language attending the children's tale of adventure.

More significant for our purposes is where the child reader and the mature reader overlap. We find this point of contact in Humpty Dumpty's explanation of the poem. The logical leaps and reasoning applied by Humpty Dumpty reveal an interpretive strategy that is more complex than it first appears. Alice asks Humpty Dumpty to explain the poem since she cannot properly understand it on her own. Humpty Dumpty has already told us his position on the meanings of words:

"When I use a word," Humpty Dumpty said in rather a scornful tone, "it means just what I choose it to mean - neither more nor less."

"The question is," said Alice, "whether you can make words mean different things."

"The question is," said Humpty Dumpty, "which is to be master-that's all".

Rather than address Alice's questions, Humpty Dumpty's explanation further complicates the problem of language in the poem, adopting a position that does not relate to the language of the poem. The emphasis on "I" steers our attention away from the language of the poem and directs us to Humpty Dumpty. This is itself a nonsense linguistic maneuver. His claims to control language from a position of singular mastery indicates another level of nonsense in the story. We have a nonsense poem, and a translation that is as unintelligible as the poem. Humpty Dumpty operates independent of any social linguistic determinants as he sets himself apart from the way language functions. This moment is a mirror of what we see in Antonin Artaud's attempt to translate "Jabberwocky": as part of a children's story, it is simple fantasy and makebelieve; as a feature of how one gains access to language, it is symptomatic of a psychotic breakdown. This can be seen as a deliberate, imaginative analogue of a psychotic break, as Humpty Dumpty proceeds according to a private logic that remains outside of the proper linguistic function. One clear symptom of schizophrenia is "formal thought disorder (manifest as disorganized speech, including the use of unusual words or phrases, and neologisms)" (Howes, Weinstein, Tabraham, Valmaggia, Broome \& McGuire, 2007: 1294). The linguistic maneuver characterized by the alleged mastery that Humpty Dumpty claims over language is in fact a further occlusion of meaning. Humpty Dumpty does not "master" the language of the poem. Rather, he assumes the mastery of unusual words or phrases and neologisms. His translation and exegesis are symptoms of schizophrenia, while the nonsense words remain nonsensical.

The issues that attend the private logic regarding language become more intractable even as they become ostensibly more intelligible. As Humpty Dumpty explains the language of the (C) Servicio de Publicaciones. Universidad de Murcia. All rights reserved. Print ISSN: 1578-7044; Online ISSN: 1989-6131

IJES, vol. 19 (2), 2019, pp. 1-18 doi: 10.6018/ijes.362231 
poem, he takes logical leaps that reveal workings in the text that are like the borderlines defined above. Alice recites the first stanza of the poem, and Humpty Dumpty interrupts her: "That's enough to begin with,' Humpty Dumpty interrupted: 'there are plenty of hard words there. "Brillig" means four o'clock in the afternoon-the time when you begin broiling things for dinner"'.

Here we see the application of the form of linguistic analysis without the meaningful content of this type of analysis. That is, Humpty Dumpty can access the formal procedure of a rational process without having access to the constituent features that define this type of analysis. It is as if he applied the schemata of a medical diagnosis without utilizing the process of deduction from symptoms that produces a legitimate medical diagnosis. If we allow for his association between the consonants "br-" and any other word pronounced in a similar way, we can see how his analysis works. But this is simply not how this kind of work is done. Humpty Dumpty arrives at these conclusions not through mastery but rather through an absolute refusal of mastery. It is too easy to say that texts such as these reach a nostalgic place in the heart of the adult reader. There is something far more complex in these texts precisely because these texts are distinguished as ambivalent texts. They are children's poems and they are also adult texts, because they reach a region of thought that is common to both communities of readers without either being entirely aware of the forms of thought. Our ability to simultaneously recognize nonsense and place the formal attributes of the text in a conventional arrangement indicates the presence of a space of understanding that lies at the border of both regions of comprehension. This border region can be elucidated by considering the role of nonsense in the very process of making sense. That region of nonsense that is symptomatic of mental illness can shed light on the space from which intelligibility emerges.

\section{ARTAUD, “JABBERWOCKY," AND THE LINGUISTIC BORDER}

A curious episode in the career of the nonsense poems of Lewis Carroll is the way his poems were used in the therapeutic treatment of Antonin Artaud, the avant-garde French dramatist and poet, during a period in which Artaud was suffering from serious mental illness. During his confinement in an asylum in Rodez, Artaud was given an episode from Through the Looking Glass to translate as part of his therapy. Specifically, he was given the episode in which Humpty Dumpty explains to Alice the language and meaning of "Jabberwocky." What Artaud produced was not so much a translation, but a text that buried meaning further into the clouds of nonsense. He coined French neologisms for English nonsense words, which in no way correspond to the original text. Rather than working as therapy, Artaud's "translation" revealed a realm of language and meaning that was peculiar to his madness. In the course of this process of 
"translation," the line between the clinical and the literary became equally indistinct. This would be little more than a curiosity were it not for the fact that these kinds of linguistic aberrations reveal aspects of mental illness that have everything to do with the overall function of language in any speaking subject. Artaud's experiment lays bare the blurred region of linguistic machinery that escapes the regulated order of language by which we communicate. This region of language defies the strict order of the signifier, an order that demands coherence and accord with symbolic psychic structures. The work of language that we have come to define as artistic or literary plays with language quite consciously. Artaud's pathological linguistic forms operate in a borderline realm of language and meaning, a psychological space in which access to language becomes occluded but not entirely lost.

Artaud's encounter with the nonsense poems of Lewis Carroll was intended be a form of therapy. Instead, this encounter revealed some crucial features of language that underpin literary language in general. Artaud was able to create his own linguistic sense, which breaks from the original English but retains the form (if not the function) of language. Artaud's poetic translation gave way to another level of nonsense, a nonsense that coheres in ways that are analogous to the original nonsense; it is here that we find a window into linguistic operations that are on the border of the sane and the insane, the signifying function of language itself, and the border between literary language and language in general. Lukes (2013) explains that in Artaud's translation, we arrive at the border between the clinical and the literary:

Because grammatical and syntactical coherence is what sustains the logical structure of language and, ultimately, holds language together, disrupting syntax amounts to chaos, silence, or madness. Yet what this cursory reading fails to grasp is the importance that derives from the fact that Artaud's broken language and cries find their origin in a process of translation. As indicators of singularity, his invented syllables and guttural cries intern their utterer within the walls of his utterance; but, as products of translation (albeit of an unconventional nature), they propel their author into a skewed conversation with another voice, establishing and subverting a literary and cultural filiation with the genre of nonsensewriting. (Lukes, 2013: 107)

If we stop at the fact that Artaud ultimately failed to translate Carroll's language and thereby further enclosed himself in the prison of his own delusional state, we fail to see that the "unregulated" psyche, as it grapples with nonsense, actually finds a point of purchase that shines a light on the mechanism of nonsense, especially in relation to more commonly accepted language. The signifying function, which is alleged to attend the fully integrated self or ego, is never completely removed from the border phase in which the ego experiments with the 
signifying function without properly being integrated into the symbolic order that regulates language and structures the ego. The physician attending Artaud, Dr. Ferdière, understood that Artaud's creations had blurred the lines between the sane and the insane. What is more important for our purposes is that this border or blurred line cuts across the clinical and the critical:

Ferdière brings together examples of verbal creation taken from translations of Carroll, children's nursery rhymes, poets' verbal collages, and schizophrenics' utterances, with a view to examining the unstable boundary between 'santé' and 'maladie mentale'. From these comments it becomes apparent that the context in which Artaud's translation was solicited and produced is one that conjoins the medical and literary fields; in such a context, translation becomes an activity that lies at the intersection of the clinical and the critical, treading a fine line between madness and therapy. (Lukes, 2013: 108)

The psychological structures at work in the language games found in Artaud's translation and in Carroll's nonsense poem further reveal the thin line between meaning and nonsense, sane and insane, and the clinical and the literary.

Lacan's famous formula, S/s, would situate language acquisition and the integration of the ego in a strict direction. As one emerges as a fully integrated ego and assumes the signifying function of language - that is, as subjectivity is sutured onto the regulating mechanisms of the symbolic order - the outcome is clear-cut: one enters into language, and the ego is fully formed. That is all. What this means is that the signifier takes primacy over the signified in the course of the normal function of language. The meaning of a word is derived from its relation to other words. This is a social relation. The normal workings of an integrated self in a socially cohesive structure finds access to language from within this system. Nonetheless, Julia Kristeva (1982) intervenes on this strict system of order, arguing for a more indistinct realm of language and meaning that cannot be entirely contained in the order of S/s. Shuli Barzilai (1991) emphasizes Kristeva's theories of the borders in her critique of the Lacanian formula. Following Kristeva, Barzilai emphasizes the fact that some so-called pathological language functions are in fact creative rather than strictly pathological. Barzilai explains that "the algorithm [Lacan's S/s] inadequately accounts for nondiscursive pathological and creative phenomena, for an experiential dimension (whether lived or, say, literary) that eludes the language function" (Barzilai, 1991: 294). These pathological and creative phenomena certainly can be pathological symptoms of mental illness. However, these same phenomena can also consist of the creative use of language, which deliberately manipulates the codified order of a signifying function. It should come as no surprise that Freud was just as interested in jokes as he was in dreams. Part of the reason certain types of humor strike us as funny is because it manipulates our sense of order in 
relation to the symbolic. Something is funny because it does not "add up" in terms of how a given form of meaning should unfold.

Barzilai is careful to point out that these language games reveal a border rather than a legitimate transgression. One cannot, ultimately, step out of the symbolic order, because this is the only way any kind of meaning can exist. The social relations, both conscious and unconscious, are the product of language and subjectivity: "The borderline is where the sovereignty of the sign is threatened and where something wild, something irreducible to language, emerges. Nevertheless, it should be noted that this is a border, not a beyond, of language. The dissolution of the sign is, Kristeva stresses, only 'relative', and a 'semblance of socialization' is sometimes maintained" (Barzilai, 1991: 295).

Yet, it is this border that demonstrates the locus of the literary force of the nonsense poem, and poetry more generally: "The borders of the symbolic system are where art, or certain types of art, emerges as well" (296). At the outer reaches of the unconscious symbolic order, we find the linguistic and psychological conditions of possibility for literary language. That this language abuts the border of the literary, the clinical, and the insane is all due to the fact that this type of language does not properly conform to the strict definitions of how language is alleged to function. Literary language operates at or near the terrain of the language of psychosis (Ibid.: 296). This border region of language and subjectivity made it possible for Artaud, in the throes of madness, to latch onto another language that is ostensibly a language of madness, and ultimately produce another mad language. The nonsense poem forces literary language further out to the margins of sanity, even as the starting point for poetic language was one that comes close to the language of psychosis.

One final but absolutely crucial point Barzilai offers is that this border area of language is preserved in the unconscious. The borderline is not a phase through which a subject passes and then proceeds to full subjectivity and maturity, leaving behind this phase of transition. The border region of language acquisition, which plays at language without coming fully under the domination of the symbolic order, is a feature of human subjectivity, and this remains within the unconscious, albeit repressed. Again, drawing on Kristeva, Barzilai explains that the borderline is not a special case of language, but rather a feature of language in general: "This 'special' case is an epitome of the speaking subject at large; instead of regarding the borderline as a pathological entity, Kristeva sees in it a pervasive aspect of the human condition. Border effects are to be found in the discourse of everyday life" (Ibid.: 296). 


\section{OPENING SPACE FOR LITERARY SIGNIFICANCE VIA BORDERLINE LANGUAGE}

The borderline of language, which reveals the symptoms of insanity and allows for the creation of poetic language, also opens us to multiple modes of accessibility for ambivalent literary texts such as children's nonsense poems.

Artaud performed nearly identical linguistic maneuvers in his translation of the same text. Artaud's translation, mediated through profound mental illness, transformed Carroll's language into a kind of French nonsense language that defies further translation. In fact, what happens in Humpty Dumpty's interpretation of "Jabberwocky" is almost identical to the textual and linguistic mutilation that occurs in Artaud's delusional translations. Lukes shows us how far afield Artaud's text becomes as she explains the type of mangling of language that occurs in his text:

The reader's sense of unease reaches its apex when he is confronted with a block of apparently incomprehensible syllabic units, set off from the rest of the text, that purport to be a paragraph-translation of Carroll's one-word poem title "Jabberwocky":

NEANT OMO NOTAR NEMO

Jurigastri-Solargultri

Gabar Uli-Barangoumti

Oltar Ufi-Sarangmumpti

Sofar Ami-Tantar Upti Momar

Uni-Septfar Esti

Gonpar Arak-Alak Eli (Lukes, 2013: 106)

These lines constitute Artaud's translation of the title, not the opening lines of the poem. This demonstrates the extent to which mental illness disturbs language function. Both Artaud and Humpty Dumpy reveal the uncodified realm of language, which operates in the borderline between non-language and language that is rigidly codified and ordered by the unconscious symbolic.

"Brillig" is obviously a made-up word. It does, however, function as a signifier. The signified can only be conjectured based on context. On the one hand, Humpty Dumpty's conclusion is as good as anyone's. On the other hand, there is no support for any conclusion. The object - the signified - simply does not exist except to the extent that we as readers are able to conjure some collection of ideas that suit the purpose: to create meaning in the poem. What unfolds in the exchange between Alice and Humpty Dumpty takes on the appearance of a break between signifier and signified. We can see the effacement not of the signifier and the signified, 
but of the social function that renders the signifier meaningful at all. It is cut off from its only function, which is to attach meaning to a social system of meaning, that is, to attach the subject to a social register of self-awareness in language.

In addition to this pseudo-psychotic detachment from the signifying process, Humpty Dumpty's next textual gloss consists of his well-known use of portmanteau words. When asked the meaning of "slithy," Humpty Dumpty explains: "Well, 'slithy' means 'lithe and slimy.' 'Lithe' is the same as 'active.' You see it's like a portmanteau - there are two meanings packed into one word." The portmanteau works to the extent that it makes sense of a word that otherwise is completely inexplicable. On the other hand, the portmanteau creates yet another potential problem. The sublation of one term to another, which is a central component to the formation of signifiers in the social register, is left incomplete in the case of the portmanteau.5 There is no synthesis in the course of the dialectic of terms that give rise to a word.

A term takes its meaning in relation to another term. This is the fundamental feature of linguistics. In this way, all words are effectively metaphors. The English term "moon" comes from the Latin mensis, which means month or the cycle of the moon. The French word "lune" is derived from the Latin lux, meaning light. Words do not correspond to things. They correspond to other words, and this is what is meant by the signifying chain that gives us unified language and speech. The portmanteau word effectively nullifies the metaphorical process by which a word is formed. In order for lux to become lune, the second term must negate the first while preserving the idea intrinsic to the first term; in this way, the second term emerges as the signifier, which signifies a cultural and social understanding of the celestial object in the sky. In the case of the portmanteau word, both terms are preserved. On the one hand, this language game is part of the appeal for the child reader especially. On the other hand, the presence of a portmanteau word presents us with a problematic psychological aspect of the text.

The dialectical work of metaphor operates in terms of Freud's "Mourning and Melancholia." The movement from one term to another necessarily entails the loss of one object in favor of another, even as this process preserves some feature of meaning from the lost object.6 The meaning of the first term is preserved in the second by way of the dialectic of mourning and melancholia. When one loses a loved one, the loss will naturally trigger an intense longing for the lost object. The psychic investment in this object cannot be withdrawn easily, and the subject will cling to the object even in its absence. The work of mourning is the primary path of psychic energy, and the libidinal investment in the lost object will finally be resolved as the unconscious becomes able to introject some notional aspect of the lost object into the grieving ego. The psychological process allows the grieving subject to retain a notional feature of the lost object and incorporates this feature into the ego. This is the proper resolution to loss. In the case of melancholia, no such resolution occurs, and the ego will endlessly substitute other objects in (C) Servicio de Publicaciones. Universidad de Murcia. All rights reserved. Print ISSN: 1578-7044; Online ISSN: 1989-6131

IJES, vol. 19 (2), 2019, pp. 1-18 doi: 10.6018/ijes.362231 
place of the lost object. The libidinal investment is in loss itself. This becomes manifest in obvious symptoms of melancholia, but it is also manifest in the form of fetish objects: substitute objects that carry some form of unconscious association with the lost object (Freud, 1917: 15455). In melancholia, there is a disavowal of the objective world in favor of a pathological libidinal investment in a lost, loved object. The subject runs toward a narcissistic investment in which they refuse to mourn the lost object and become psychologically invested in loss itself. In this case, phantasmatic objects will necessarily stand in for an object which simply does not exist in objective reality. This is, in fact, precisely what occurs in the case of the portmanteau word. A term such as "slithy," and Humpty Dumpty's explanation of the term, leaves in place the two terms for objects without ever resolving the conflict between the presence of one object and another. This does not preserve the meaning of both words, but rather, creates the space for a phantasm that displaces both terms. Humpty Dumpty's explanation fails not because it is illogical, but because it fails to account for the truly phantasmatic character of a slithy object. It is not real and cannot be made to be real. This has affinities with melancholic irresolution, which is pathological rather than charming.

Yet, this same process is the realm in which the objects of poetic language can emerge. In preserving multiple valences of meaning, poetic language can manipulate the processes of mourning and melancholia to produce varying levels of meaning. A central difference between poetic language and ordinary rhetorical forms entails a deliberate modification, or "deformation," to use Shavit's term. As Giorgio Agamben explains: "If the external world is in fact narcissistically denied to the melancholic as an object of love, the phantasm yet receives from this negation a reality principle and emerges from the mute interior crypt in order to enter into a new and fundamental dimension. No longer a phantasm and not yet a sign, the unreal object of melancholy introjection opens a space that is neither the hallucinated oneiric scene of phantasms nor the indifferent world of natural objects" (Agamben, 1993: 25).

The "space" Agamben describes is in fact that borderline space that Barzilai introduces from Kristeva. It is in this borderline area that we encounter the space, or topology in Agamben's terms, of the poetic, the mad, and the child: "The topology that is here expressed tentatively in the language of psychology has always been known to children, fetishists, 'savages,' and poets" (Ibid.: 59). The ambivalent text reaches and reveals this borderline, and it is the common access to this borderline in both children and adults that renders some "children's" literature particularly appealing to both mature and immature readers.

Portmanteau words and the illogical claims of mastery that defy the social realm may be symptoms of insanity, as in Artaud's delusional appropriation of Through the Looking Glass and his belief that Carroll plagiarized Artaud's work, even though Carroll had written nearly a hundred years prior. At the same time, these types of linguistic games are at the heart of poetic (C) Servicio de Publicaciones. Universidad de Murcia. All rights reserved. 
language and of the playful use of language by children-even children who have not fully mastered language. The ambivalent text is particularly adept at dwelling in this borderline space of meaning, this region in which meaning has not gained mastery over the speaking subject and has not been fully integrated into strict signifying functions. The pleasure of the text for both adults and children lies in "a pleasure originating in the vacuity of meaning and of the signifier that is lacking in logical discourse" (Marret, 1993). This lack of meaning and logic reveals the play that is at work in the borderline.

\section{CONCLUSION}

The borderline preserves the undifferentiated and phantasmatic play of meaning that underpins any subjective access to language. While the borderline becomes visible in the symptoms of psychosis, it is due to the pathological breakdown of the language function with respect to subjectivity and the subjective integrity of the mentally ill. For healthy readers, we gain access to the types of language characteristic of the borderline via poetic language. Nonsense language and nonsense poems, which are most often aimed at child readers, offer a striking case of poetic language that operates squarely on the borderline at the recesses of language functions. The case of Artaud shows us that symptoms of madness as expressed in nonsense language operate in the same terrain as the nonsense of children's poetry. Artaud's translation makes as much sense as the exegesis given by Carroll as Humpty Dumpty. Since this border region of language is retained by the healthy adult reader, it would appear that a text such as "Jabberwocky" can speak to both the child and adult reader because it speaks to a region of understanding common to both, and is simultaneously implicit in the interpretive strategies of both. Children's literature, particularly those texts that reach across the literary-didactic split, contain meanings that are at the edge of functioning language, but which nevertheless reach the realm of systematized language.

\section{NOTES}

${ }^{1}$ James Kincaid offers a complex analysis of the literary/historical invention of the child and childhood. Again, childhood - and by extension, children's literature - are historical contingencies that cannot be pinned down to a stable category: "The child is not a fixed counter, even in photographs, and acts not simply as a distant allurement but as a moving conveyer belt, propelling the adult dreamer into the child' s world, a world that immediately becomes the sole property of the dreamer" (Kincaid, 1991: 4). In Kincaid's view, childhood and the child are projections of the adult. 
${ }^{2}$ Even Lear's "The Jumblies" is treated as a symptom of Victorian cultural anxieties. The antagonism between one's allegiance to the social order and the demand to express oneself is seen as one such cultural conflict at work in Lear's nonsense poetry. It is precisely through the poetic play of nonsense that we see how "he addresses himself to the plight of the individual faced with either a nameless mass society or an indifferent Nature before whom he is distinctly alone and 'other"' (Hark, 1978: 113).

${ }^{3}$ A reference to Beowulf: A New Verse Translation (Heaney, 2000).

${ }^{4}$ The turn toward the "I" is indicative of schizophrenia. The hyper-reflexivity that leads to a dissolution of the self is first manifested as a morbid preoccupation with the self. It is this turn inward that Sass cites as symptomatic of schizophrenia. These symptoms indicate hyper-rationality as opposed to conventional accounts of schizophrenia. As Sass explains, schizophrenia is "far from necessarily sustaining a sense of self, a strong observing ego may actually undermine it. Dissolution of self need not, it seems, necessarily be taken as indicating a primitive or Dionysian absence of reflective awareness" (Sass, 1987: 18). Humpty Dumpty displays the onset of schizophrenic symptoms with his rhetorical maneuver of mastery over language.

${ }^{5}$ On semiotics, metaphor, and sublation, see Rowlinson (1993).

${ }^{6}$ For a sustained analysis of the structure and function of metaphor, see Sobolev (2008).

\section{ACNOWLEDGEMENTS}

This research was funded by Children's Literature Chair at Princess Noura bint Abdulrahman University (Grant no: CLS-2018-14) Saudi British Centre.

\section{REFERENCES}

Agamben, G. (1993). Stanzas: Word and Phantasm in Western Culture. U of Minnesota Press. Barzilai, S. (1991). Borders of language: Kristeva's critique of Lacan. PMLA, 106(2), 294-305.

Beardsley, M. (1981). Aesthetics: Problems in the Philosophy of Criticism. Indianapolis, IN: Harcourt, Brace, and World.

Bourdieu, P. (1984). Distinction: A Social Critique of the Judgement of Taste. Abingdon: Routledge.

Carroll, L. (1931). The Lewis Carroll Book (R. Herrick, Ed.): New York, NY. The Dial Press.

Eveloff, H. (1971). Some cognitive and affective aspects of early language development. Child Development, 42(6), 1895-1907.

Freud, S. (1986). The Standard Edition of the Complete Works of Sigmund Freud, Vol. XIV (J. Strachey, Trans.). London: The Hogarth Press.

(C) Servicio de Publicaciones. Universidad de Murcia. All rights reserved. Print ISSN: 1578-7044; Online ISSN: 1989-6131
IJES, vol. 19 (2), 2019, pp. 1-18 doi: 10.6018/ijes.362231 
Gubar, M. (2011). On not defining children's literature. PMLA 126(1), 209-216.

Hark, I. R. (1978). Edward Lear: Eccentricity and Victorian angst. Victorian Poetry, 16(1/2), 112-122.

Heaney, S. (Trans). (2000). Beowulf: A New Verse Translation. New York, NY: Farrar, Strauss, and Giroux.

Holquist, M. (1999). What is a Boojum? Nonsense and modernism. Yale French Studies, 96, 100-117.

Howes, O. D., Weinstein, S., Tabraham, P. Valmaggia, L., Broome, M. \& McGuire, P. (2007). Slang and schizophrenia. BMJ: British Medical Journal, 335(7633), 1294-1294.

Kincaid, J. (1991). The manufacture and consumption of children. Victorian Review, 17(1), 1-17.

Kristeva, J. (1982). Powers of Horror: An Essay on Abjection (L. Roudiez, Trans.). New York, NY: Columbia University Press.

Kutzer, M. D. (1981). Children's literature in the college classroom. College English, 43(7), 716-723.

Lukes, A. (2013). The asylum of nonsense: Antonin Artaud's translation of Lewis Carroll. Romantic Review, 104(1/2), 105-126.

Marret, S. (1993). Metalanguage in Lewis Carroll. SubStance, 22(2/3).

Nikolajeva, M. (2005). Aesthetic Approaches to Children's Literature: An Introduction. Maryland, MD: Scarecrow Press.

Rother, J. (1974). Modernism and the nonsense style. Contemporary Literature, 15(2), 187-202.

Rowlinson, M. (1993). Mourning and metaphor: On the literality of Tennyson's "Ulysses." Boundary, 20(2), 230-265.

Rundus, R. J. (1967). “O frabjous day!”: Introducing poetry. The English Journal, 56(7), 958-63.

Sass, L. A. (1987) Introspection, schizophrenia, and the fragmentation of self. Representations (19), 134.

Schatz, S. L. (2015). Lewis Carroll's dream-child and Victorian child psychopathology. Journal of the History of Ideas, 76(1), 93-114.

Sobolev, D. (2008). Metaphor revisited. New Literary History, 39(4), 903-929.

Vallone, L. (1998). Children's literature within and without the profession. College Literature, 25(2), $137-145$.

Williams, J. A. (2013). Lewis Carroll and the private life of words. The Review of English Studies, 64(266), 651-671.

(C) Servicio de Publicaciones. Universidad de Murcia. All rights reserved. Print ISSN: 1578-7044; Online ISSN: 1989-6131
IJES, vol. 19 (2), 2019, pp. 1-18 doi: 10.6018/ijes.362231 